\title{
Phenotypic Characterization of Multifungicide Resistance in Botrytis cinerea Isolates from Strawberry Fields in Florida
}

\author{
A. Amiri, S. M. Heath, and N. A. Peres, University of Florida, Gulf Coast Research and Education Center, Wimauma, FL 33598
}

\begin{abstract}
Amiri, A., Heath, S. M., and Peres, N. A. 2013. Phenotypic characterization of multifungicide resistance in Botrytis cinerea isolates from strawberry fields in Florida. Plant Dis. 97:393-401.

Chemical control has always been essential for the management of gray mold, caused by Botrytis cinerea, to ensure sustainable strawberry production. However, lack of knowledge about actual resistance development may have disastrous consequences and lead to severe epidemics such as the one that affected several strawberry fields in 2012 in Florida. In this study, we tested 392 isolates collected from Florida strawberry fields between 2010 and 2012 for their sensitivity to boscalid (Bosc), a succinate dehydrogenase inhibitor (SdhI); pyraclostrobin, a quinone outside inhibitor (QoI); boscalid + pyraclostrobin (Pristine); fenhexamid, a hydroxyanilide (Hyd); pyrimethanil and cyprodinil, anilinopyrimidines; fludioxonil, a phenylpyrrole; and fludioxonil + cyprodinil (Switch). The respective resistance frequencies for boscalid, pyraclostrobin, Pristine, fenhexamid, cyprodinil, and pyrimethanil were 85.4, 86.5, 86.0, 44.4, 52.7, and 59.5\%. Overall, 17.8 and $19.8 \%$ of isolates showed reduced sensitivity to fludioxonil and

Switch, respectively. All fungicides sprayed preventively on detached strawberry fruit failed to control isolates with high levels of resistance to each fungicide except for fludioxonil and Switch. Four phenotypes with multifungicide resistance (MFR) were detected in $B$. cinerea populations from Florida. Isolates resistant to one fungicide (FR1), two (MFR2), three (MFR3), and four (MFR4) fungicides from different chemical groups represented 5.9, 28.6, 41.8, and $23.7 \%$ of the total resistant population, respectively. The MFR3 isolates were predominant and contained two subpopulations, the Bosc-QoI-APR isolates $(56.5 \%)$ and the Bosc-QoI-Hyd ${ }^{\mathrm{R}}$ isolates $(40.6 \%)$. In addition to reporting on very highly resistant populations to boscalid and QoI fungicides, we show evidence for a widespread multifungicide resistance to $B$. cinerea that warrants immediate implementation of novel management strategies to impede the development of more resistant populations.
\end{abstract}

Gray mold, also known as Botrytis fruit rot, caused by Botrytis cinerea Pers.:Fr. (teleomorph Botryotinia fuckeliana), represents a major threat for strawberry production in Florida, the second largest production region in the United States, as well as in many other growing areas worldwide. The fungus infects flowers but is more damaging to fruits pre- and postharvest, especially under favorable conditions, i.e., temperatures around $20^{\circ} \mathrm{C}$ and prolonged periods of high humidity. Such conditions are commonly encountered in Florida during the production period between November and March. Quiescent infections start on young strawberry leaves early in the season, and conidia produced on necrotic tissues serve as the primary inoculum source. Conidia are dispersed mainly by wind and insects to infect flowers. Infections usually remain quiescent in immature fruit until conditions become favorable for disease development $(7,8,32)$.

Current strategies used to control gray mold in strawberry rely on preventive applications of fungicides from multiple chemical groups. Besides the multi-site fungicides captan and thiram, compounds from five different chemical groups, i.e., succinate dehydrogenase inhibitors (SdhI), quinone outside inhibitors (QoI, suppression), hydroxyanilides (Hyd), anilinopyrimidines (AP), and phenylpyrroles (PP) are registered for gray mold control in Florida (38) and worldwide. In Florida, a standard disease management program consists of weekly applications of the multi-site fungicides throughout the season and single-site fungicides such as fenhexamid, pyrimethanil, pyraclostrobin + boscalid (Pristine), and

Corresponding author: N. A. Peres, E-mail: nperes@ufl.edu

* The $\boldsymbol{e}$-Xtra logo stands for "electronic extra" and indicates that a supplementary figure is available online.

Accepted for publication 9 October 2012.

http://dx.doi.org/10.1094/PDIS-08-12-0748-RE

(C) 2013 The American Phytopathological Society cyprodinil + fludioxonil (Switch) during the main peak bloom periods, which vary depending on the cultivar (33). In addition to pyraclostrobin, a component of Pristine and also available as a single product (Cabrio), other QoIs such as azoxystrobin and trifloxystrobin represent the mainstay of anthracnose fruit rot (AFR) (caused by Colletotrichum acutatum) control in Florida strawberry fields $(34,38)$. The total number of applications of QoI fungicides for AFR control and suppression of gray mold is limited to five per season in Florida. Although not yet investigated in strawberry fields in Florida, populations of $B$. cinerea resistant to the QoIs and boscalid are widespread in strawberry fields as well as in many other crops worldwide $(12,19,28,39,41)$.

The anilinopyrimidines (pyrimethanil and cyprodinil) and phenylpyrroles (fludioxonil) are commonly used to protect the flowers against gray mold during the peak bloom period. Pyrimethanil is registered as a single fungicide (Scala), whereas cyprodinil is combined with fludioxonil in a pre-packaged mixture (Switch). The APs act on fungi by inhibiting the secretion of hydrolytic enzymes essential during infection as well as by targeting the synthesis of methionine and other amino acids (16,30). Populations of $\mathrm{B}$. $\mathrm{ci}$ nerea resistant to pyrimethanil and cyprodinil have been already reported in French vineyards (27) and vegetable fields in Greece (35). Fludioxonil, the sole PP registered for gray mold management, is very effective against conidial germination and mycelial growth. Most likely, fludioxonil causes an increase in glycerol accumulation in the fungal cells as a result of its interference with the signal transduction pathway (36). Laboratory and field $B$. cinerea mutants showing reduced sensitivity to fludioxonil have been selected $(17,27,43)$; however, resistance to this fungicide has not been yet reported in the field.

The hydroxyanilide fenhexamid has a different mode of action than the previously mentioned fungicides. It is a protectant and locally systemic fungicide proven to reduce colonization of flowers by $B$. cinerea and to enhance control of gray mold in strawberries $(25,26,32)$. Fenhexamid targets the 3-keto reductase (3-KR), one of the three microsomal enzymes involved in the inhibition of the C4demethylation complex $(9,22)$. Resistance to fenhexamid in $B$. 
cinerea has been reported in French and Chilean vineyards $(2,10,13)$ and in a single case from different vegetables in Greece (35). Resistance to fenhexamid in $B$. cinerea has been linked to a point mutation at codon 412 in the erg 27 gene encoding for the 3-KR enzyme (13). This mutation was found to be deleterious to mutants carrying it in comparison to the wild-type isolates under laboratory conditions (6). The extent to which these isolates can persist in the field and cause control failures is unknown.

A severe gray mold epidemic affected many strawberry fields in Florida in February 2012 and caused high yield losses. Such situations warrant detailed information regarding the occurrence of $B$. cinerea populations resistant to the most common fungicides in use to provide scientifically based recommendations and to avoid a total control failure. Therefore, this study was intended to (i) determine the level of in vitro and in vivo sensitivities to quinone outside inhibitors, succinate dehydrogenase inhibitors, hydroxyanilides, phenylpyrroles, and anilinopyrimidines in $B$. cinerea populations collected from commercial strawberry fields in Florida, and (ii) investigate the multifungicide resistance and crossresistance patterns.

\section{Materials and Methods}

Fungal isolates. A total of $392 \mathrm{~B}$. cinerea isolates collected over a 3-year period between 2010 and 2012 from commercial strawberry fields were used in this study (Table 1). Isolates were collected from nine fields in Hillsborough County, where the majority of strawberries are grown in Florida, and from one field in Citrus County. Single-spore isolates were grown on malt yeast agar (MYA) medium for 1 week and stored in $20 \%$ glycerol at $-80^{\circ} \mathrm{C}$. Conidial suspensions for in vitro and in vivo experiments were prepared from new cultures grown from the stock for 7 days at $23^{\circ} \mathrm{C}$ on $2 \%$ malt extract agar for each new experiment. The conidia were scraped from the surface of the culture, suspended in 15 $\mathrm{ml}$ of sterile distilled water containing $0.05 \%$ Tween 80 , and filtered through cheesecloth. The concentration was determined using a hemacytometer and adjusted to a final concentration of $10^{6} \mathrm{co}-$ nidia/ml.

Fungicides. All isolates were tested for their sensitivity to boscalid (Endura, BASF Crop Protection, Research Triangle Park, NC), pyraclostrobin (Cabrio EC, BASF), pyrimethanil (Scala SC, Bayer CropScience, Research Triangle Park, NC), cyprodinil (Vanguard WG, Syngenta Crop Protection, Greensboro, NC), fludioxonil (Medallion WP, Syngenta), and fenhexamid (Elevate WDG, Arysta LifeScience, Cary, NC), whereas 150 isolates were tested for boscalid + pyraclostrobin (Pristine, BASF) and cyprodinil + fludioxonil (Switch WG, Syngenta). These fungicides are the most commonly used to control gray mold in Florida. The characteristics of the fungicides and the concentrations used are summarized in Table 2. For simplicity, the mixtures of boscalid + pyraclostrobin and cyprodinil + fludioxonil are referred to as Pristine and Switch, respectively, throughout the manuscript. Stock solutions of the fungicides were prepared in $10 \mathrm{ml}$ of sterile distilled water and stored at $4^{\circ}$ C. Salicylhydroxamic acid (SHAM) was added at 100 $\mu \mathrm{g} / \mathrm{ml}$ to autoclaved media to test for sensitivity to pyraclostrobin and Pristine.

Media. The sensitivity to cyprodinil and pyrimethanil was evaluated using mycelial growth inhibition tests on a minimal CzapeKDox agar medium (CzA) containing $2 \mathrm{~g} \mathrm{NaNO}_{3}, 0.5 \mathrm{~g} \mathrm{KCl}, 0.5 \mathrm{~g}$ $\mathrm{MgSO}_{4} \cdot 7 \mathrm{H}_{2} \mathrm{O}, 0.01 \mathrm{~g} \mathrm{Fe}_{2} \mathrm{SO}_{4}, 1 \mathrm{~g} \mathrm{~K}_{2} \mathrm{HPO}_{4}, 0.01 \mathrm{~g} \mathrm{ZnSO}_{4} ; 0.005 \mathrm{~g}$ $\mathrm{CuSO}_{4} \cdot 5 \mathrm{H}_{2} \mathrm{O}, 30 \mathrm{~g}$ sucrose, and $12 \mathrm{~g}$ agar in 1.0 liter of distilled water (29). The sensitivity to fludioxonil and Switch was determined on CzA amended with $5 \mathrm{~g} /$ liter yeast extract. The sensitivity

Table 1. Origin of Botrytis cinerea isolates used in this study

\begin{tabular}{|c|c|c|c|c|c|c|}
\hline \multirow[b]{2}{*}{ County } & \multirow[b]{2}{*}{ City } & \multirow[b]{2}{*}{ Location $^{\mathrm{z}}$} & \multicolumn{4}{|c|}{ Number of isolates ${ }^{y}$} \\
\hline & & & $n$ total & 2010 & 2011 & 2012 \\
\hline \multirow[t]{9}{*}{ Hillsborough } & Balm & GC & 70 & 17 & 10 & 43 \\
\hline & Balm & BBY & 22 & 0 & 0 & 22 \\
\hline & Balm & ASB & 22 & 0 & 0 & 22 \\
\hline & Dover & $\mathrm{PC}$ & 50 & 6 & 12 & 32 \\
\hline & Dover & SS & 61 & 8 & 13 & 40 \\
\hline & Dover & AN & 27 & 5 & 14 & 8 \\
\hline & Dover & BI & 31 & 5 & 10 & 16 \\
\hline & Dover & ASD & 23 & 0 & 0 & 23 \\
\hline & Plant City & FY & 57 & 5 & 13 & 39 \\
\hline Citrus & Floral City & FS & 29 & 0 & 0 & 29 \\
\hline Total & & & 392 & 46 & 72 & 274 \\
\hline
\end{tabular}

${ }^{\mathrm{y}}$ Total number of isolates per location and the number of isolates collected per location in each year.

${ }^{\mathrm{z}}$ Abbreviation code corresponding to each surveyed strawberry field.

Table 2. Characteristics, concentration, ranges, and recommended field rates of fungicides used in this study

\begin{tabular}{|c|c|c|c|c|c|c|}
\hline Active ingredient (a.i.) & Trade name & $\%$ a.i. & Chemical group $^{v}$ & $\begin{array}{c}\text { Stock solutions a.i. } \\
(\mu \mathrm{g} / \mathrm{ml})^{\mathrm{w}}\end{array}$ & $\begin{array}{c}\text { Range } \\
(\mu \mathrm{g} / \mathrm{ml})^{\mathrm{x}}\end{array}$ & $\begin{array}{l}\text { Recommended } \\
\text { field rate/liter }\end{array}$ \\
\hline Boscalid & Endura & 70.0 & SdhI & $\begin{array}{r}880.0^{y} \\
56,900.0^{y}\end{array}$ & $\begin{array}{l}0.05 \text { to } 5 \\
3.63 \text { to }>688\end{array}$ & $0.86 \mathrm{~g}$ \\
\hline Pyraclostrobin & Cabrio & 20.0 & QoI & $\begin{array}{r}187.0^{y} \\
61,100.0^{y}\end{array}$ & $\begin{array}{l}0.01 \text { to } 1 \\
3.5 \text { to }>711\end{array}$ & $1.09 \mathrm{~g}$ \\
\hline Boscalid + pyraclostrobin ${ }^{z}$ & Pristine & $25.2+12.8$ & $\mathrm{SdhI}+\mathrm{QoI}$ & $57,000.0$ & 0.73 to $137.6 / 1.11$ to 225.11 & $1.79 \mathrm{~g}$ \\
\hline Pyrimethanil & Scala SC & 54.6 & AP & $28,548.7$ & $<0.79$ to 200 & $1.4 \mathrm{ml}$ \\
\hline Cyprodinil & Vangard WG & 75.0 & AP & $15,023.5$ & $<0.69$ to 100 & $0.7 \mathrm{~g}$ \\
\hline Fludioxonil & Medallion WP & 50.0 & PP & 78.1 & 0.005 to 0.5 & $2.5 \mathrm{~g}$ \\
\hline Fludioxonil + cyprodinil $^{\mathrm{z}}$ & Switch WG & $25.0+37.5$ & $\mathrm{AP}+\mathrm{PP}$ & $152.6(62.5+90.1)$ & 0.004 to $0.4 / 0.006$ to 0.6 & $1.05 \mathrm{~g}$ \\
\hline Fenhexamid & Elevate WDG & 50.0 & Hyd & $\begin{array}{r}84.2^{\mathrm{y}} \\
16,834 \cdot 1^{y}\end{array}$ & $\begin{array}{l}0.004 \text { to } 0.66 \\
0.75 \text { to } 132.3\end{array}$ & $1.8 \mathrm{~g}$ \\
\hline
\end{tabular}

${ }^{\mathrm{v}}$ QoI, SdhI, Hyd, PP, and AP indicate quinone-outside inhibitors, succinate dehydrogenase inhibitor, hydroxyanilide, phenylpyrroles, and anilinopyrimidines, respectively.

${ }^{\mathrm{w}}$ Concentrations of the active ingredient predetermined by the spiral gradient endpoint (SGE).

${ }^{\mathrm{x}}$ Radial concentration range from the center to the perimeter of the plate.

${ }^{y}$ Lower and higher concentrations were used to test for low and high resistance to each fungicide, respectively.

${ }^{\mathrm{z}}$ Sensitivity to Pristine and Switch was determined on 150 isolates. 
to pyraclostrobin and fenhexamid was evaluated on potato dextrose agar (PDA) using a mycelial growth inhibition test because the latter was found to be accurate in characterizing resistant from sensitive isolates $(3,19,21,29)$. The sensitivity to boscalid was assessed using conidial germination tests on water agar (WA) based on results from previous studies $(3,42)$. Media were prepared at least $12 \mathrm{~h}$ before each experiment as explained below.

In vitro phenotyping of isolates. The sensitivity of isolates was determined using the spiral gradient dilution method developed previously by Förster et al. (15) except that cellophane strips were replaced with agar strips to simplify the inoculation step. To produce the agar strips, 70 to $80 \mathrm{ml}$ of MYA containing $20 \mathrm{~g} /$ liter of agar was poured into $15-\mathrm{cm}$-diameter petri dishes to obtain a 4 - to 5 -mm thick layer of agar. The MYA contained $20 \mathrm{~g}$ of agar instead of $12 \mathrm{~g} /$ liter to harden the medium and make the strips easier to manipulate for plate inoculation. The medium was amended with $0.5 \mathrm{~g} /$ liter of streptomycin and $0.2 \mathrm{~g} /$ liter ampicillin after autoclaving. For fast and more efficient production of inoculum strips, we designed an agar slicer (Supplementary Fig. 1) to produce strips with the exact dimensions required for the SGD method. Sixteen agar strips ( $9 \mathrm{~cm}$ long), obtained by pressing the agar slicer into the MYA medium, were cut perpendicularly into 32 strips $(4.5 \mathrm{~cm}$ long and $6 \mathrm{~mm}$ wide) using a sterile scalpel. One milliliter of a conidial suspension $\left(10^{6}\right.$ conidia/ml $)$ from each isolate prepared as described above was spread onto the sliced agar using a glass spreader. The plates were sealed with Parafilm and incubated for $48 \mathrm{~h}$ at $23^{\circ} \mathrm{C}$ and used for fungicide sensitivity tests as described below.

For fungicides tested using mycelial growth inhibition, $50 \mu \mathrm{l}$ of each fungicide stock solution at the concentrations indicated in Table 2 were applied spirally on 15 -cm-diameter plates containing the corresponding medium using the spiral plater (Spiral System, Autoplate 4000 model, Spiral Biotech, Norwood, MA). A duplicate mycelium-covered agar strip (from each isolate) was applied radially across the fungicide gradient dilution on each plate allowing testing two isolates per plate. Three replicate plates (six strips per isolate) were used for each fungicide. To verify that the spiral gradient was applied accurately by the spiral plater, a sensitive isolate (03-37) was tested in each experiment in addition to the test isolates. Plates were sealed in plastic bags, incubated at $23^{\circ} \mathrm{C}$, and mycelium growth was assessed after $48 \mathrm{~h}$.

To test for sensitivity to boscalid, WA plates $(15 \mathrm{~cm}$ diameter) were divided into thirds with a marker, and seven $10-\mu$ drops of a conidial suspension at $10^{6}$ conidia/ml were placed in duplicate per third along the concentration gradient using a multichannel pipette. Three isolates were tested per plate. Conidial germination was evaluated under a microscope after 16 to $24 \mathrm{~h}$ of incubation at $23^{\circ} \mathrm{C}$ to determine a point along the fungicide gradient at which $50 \%$ of conidia had germinated. Only conidia with a germ tube twice as long as their diameters were considered germinated. Two replicate plates were used for each isolate. Mycelial growth and conidial germination inhibition tests were conducted twice.

Fruit assay. The fungicides tested in this study were evaluated for their ability to control isolates with different levels of resistance on strawberry fruit. Four to five isolates with different $\mathrm{EC}_{50}$ values to the different fungicides tested were selected. Fruit (cv. Camarosa) that had never been sprayed with fungicides were harvested before commercial maturity (white-pink stage) from experimental plots at the Gulf Coast Research and Education Center (GCREC), Wimauma, FL. Fruit were washed in $0.05 \%$ sodium hypochlorite for $3 \mathrm{~min}$, rinsed twice with sterile distilled water, and allowed to dry under a laminar flow hood. Subsequently, fruit were placed in carbon-fiber trays, punctured using a 5-mm cork-borer to a depth of $4 \mathrm{~mm}$ and immediately sprayed with Scala (a.i. pyrimethanil), Endura (a.i. boscalid), Cabrio (a.i. pyraclostrobin), Vanguard (a.i. cyprodinil), Medallion (a.i. fludioxonil), Switch (a.i. cyprodinil + fludioxonil), or Elevate (a.i. fenhexamid) at field rates shown in Table 2 using a disposable spray gun (Aerove, Gardnerville, NV). Control fruit were sprayed with sterile water. Fruit were incubated for $24 \mathrm{~h}$ at room temperature, and a $40-\mu$ droplet of a conidial suspension of $B$. cinerea isolates at $10^{6}$ conidia/ml was placed on each wound. Inoculated fruit were incubated in sealed humidity chambers for 4 to 6 days, and incidence of gray mold was determined as the frequency of fruit showing disease in comparison to the watersprayed control fruit. The disease severity (DS) was estimated using the formula DS = (lesion diameter in control fruit - lesion diameter in fungicide-treated fruit)/lesion diameter in control fruit $\times 100$. Six replicate fruit were used for each isolate-fungicide combination, and the experiment was conducted twice.

Data analysis. Data from in vitro and in vivo sensitivity tests from repeated experiments were combined after homogeneity of variance between experiments was tested using Bartlett's test. The $\mathrm{EC}_{50}$ value of each isolate to the mixtures Pristine (boscalid + pyraclostrobin) and Switch (cyprodinil + fludioxonil) was determined as the sum of the two $\mathrm{EC}_{50}$ values determined for each active ingredient separately. Interaction between the two active ingredients of each mixture was calculated based on $\mathrm{EC}_{50}$ values of mycelial growth using the Abbot formula (1) as described previously (3). Pearson correlation coefficients were calculated to determine cross-resistance between different fungicides. Gray mold incidence data from fruit assays were subjected to an ANOVA, and means

Table 3. Summary of sensitivity to multiple fungicides of Botrytis cinerea isolates from strawberry fields in Florida

\begin{tabular}{|c|c|c|c|c|c|c|c|c|c|c|c|}
\hline \multirow[b]{3}{*}{ Fungicide } & \multirow{3}{*}{$\underset{(\mu \mathrm{g} / \mathrm{ml})^{\mathrm{x}}}{\operatorname{Range} \mathrm{EC}_{50}}$} & \multirow[b]{3}{*}{$\mathbf{R F}^{\mathbf{y}}$} & \multirow{3}{*}{$\begin{array}{l}\text { Resistance } \\
\text { frequency } \\
(\%)^{\mathrm{z}}\end{array}$} & \multicolumn{8}{|c|}{ Characterization and frequency of resistant phenotypes $^{w}$} \\
\hline & & & & \multicolumn{2}{|c|}{ LR/RS } & \multicolumn{2}{|c|}{ MR } & \multicolumn{2}{|l|}{ HR } & \multicolumn{2}{|c|}{ VHR } \\
\hline & & & & $\mathbf{E C}_{50}$ & $\%$ & $\mathbf{E C}_{50}$ & $\%$ & $\mathbf{E C}_{50}$ & $\%$ & $\mathbf{E C}_{50}$ & $\%$ \\
\hline Boscalid & $0.42->688$ & $>1612.0$ & 85.4 & $<5$ & 0.0 & 5 to $<50$ & 19.0 & $\geq 50$ to $<500$ & 39.0 & $>500$ & 42.0 \\
\hline Pyraclostrobin & $0.03->711$ & $>20866.0$ & 86.5 & $<5$ & 0.0 & $\ldots$ & 0.0 & 5 to $<500$ & 59.5 & $>500$ & 40.5 \\
\hline Pristine & $0.24->117$ & $>487.5$ & 86.0 & $\ldots$ & 0.0 & $\ldots$ & 0.0 & 50 to $<100$ & 42.0 & $\geq 100$ & 58.0 \\
\hline Pyrimethanil & $<0.79-125$ & 158.2 & 59.5 & 1 to $<5$ & 43.5 & $\geq 5$ to 10 & 31.8 & $>10$ & 24.7 & $\ldots$ & 0.0 \\
\hline Cyprodinil & $0.85-84.8$ & 99.8 & 52.7 & 1 to $<5$ & 56.1 & $\geq 5$ to 10 & 22.7 & $>10$ & 21.2 & $\ldots$ & 0.0 \\
\hline Fludioxonil & $0.01-0.20$ & 20.0 & 17.8 & $\geq 0.1$ & 100.0 & $\ldots$ & 0.0 & $\ldots$ & 0.0 & $\ldots$ & 0.0 \\
\hline Switch & $0.03-0.63$ & 35.8 & 19.8 & $\geq 0.1$ & 100.0 & $\ldots$ & 0.0 & $\ldots$ & 0.0 & $\ldots$ & 0.0 \\
\hline Fenhexamid & $0.06-132.3$ & 2205 & 44.4 & $\ldots$ & 0.0 & 1.46 to $<10$ & 34.8 & $>10$ & 65.2 & $\ldots$ & 0.0 \\
\hline
\end{tabular}

${ }^{\mathrm{w}}$ Isolates were characterized as LR/RS = low/reduced sensitivity, MR = moderately resistant, HR = highly resistant, VHR = very highly resistant based on the $\mathrm{EC}_{50}$ value range indicated in the column corresponding to each phenotype.

${ }^{\mathrm{x}}$ Mean effective concentrations inhibiting 50\% of mycelial growth and conidial germination after 48 and 24 h, respectively $(n=392$ except for Pristine and Switch for which 150 isolates were tested for each fungicide).

${ }^{\mathrm{y}}$ Resistance factor (RF) was calculated for each fungicide by dividing highest $\mathrm{EC}_{50}$ value by the lowest $\mathrm{EC}_{50}$ value.

${ }^{\mathrm{z}}$ Resistance frequency (reduced sensitivity [RS] for fludioxonil and Switch) was estimated based on a discriminatory $\mathrm{EC}_{50}$ obtained from the correlation between the discriminatory $\mathrm{EC}_{50}$ in vitro and the $\mathrm{EC}_{50}$ value of isolates causing gray mold on strawberry fruit when sprayed at the recommended field rate. Discriminatory dose of $5 \mu \mathrm{g} / \mathrm{ml}$ was used for boscalid, pyraclostrobin, pyrimethanil, and cyprodinil, $10 \mu \mathrm{g} / \mathrm{ml}$ for fenhexamid, and $0.1 \mu \mathrm{g} / \mathrm{ml}$ for fludioxonil (and Switch). 
were separated using Fisher's LSD test. All statistical analyses were performed using the SAS software (Version 9.2, SAS Institute Inc., Cary, NC).

\section{Results}

In vitro sensitivity of $\boldsymbol{B}$. cinerea isolates. $\mathrm{EC}_{50}$ values were the highest for pyraclostrobin and boscalid and ranged from 0.03 to $>711 \mu \mathrm{g} / \mathrm{ml}$ and from 0.42 to $>688 \mu \mathrm{g} / \mathrm{ml}$, respectively (Table 3 ), resulting in respective mean $\mathrm{EC}_{50}$ values of $>347.47$ and $>268.14$ $\mu \mathrm{g} / \mathrm{ml}$ (data not shown). Corresponding resistance factors (RF) were $>20,866$ and $>1,612$, respectively. $\mathrm{EC}_{50}$ values for Pristine ranged from 0.24 to $>177 \mu \mathrm{g} / \mathrm{ml}$ with a RF $>487.5$. The $\mathrm{RF}$ (2205) for fenhexamid was the highest after pyraclostrobin among all tested fungicides, and $\mathrm{EC}_{50}$ values ranged from 0.06 to 132.31 $\mu \mathrm{g} / \mathrm{ml}$ (Table 3).

The mean $\mathrm{EC}_{50}$ values for the APs pyrimethanil and cyprodinil were 20.79 and $10.21 \mu \mathrm{g} / \mathrm{ml}$, respectively (data not shown), and the $\mathrm{EC}_{50}$ values ranged from $<0.79$ to $125 \mu \mathrm{g} / \mathrm{ml}$ and from 0.85 to 84.8 $\mu \mathrm{g} / \mathrm{ml}$, respectively. Respective RFs were 158.2 and 99.8 (Table 3). The $\mathrm{EC}_{50}$ values for fludioxonil ranged between 0.01 and 0.20 $\mu \mathrm{g} / \mathrm{ml}$, which resulted in the lowest RF (20) among all fungicides tested in this study. The mean $\mathrm{EC}_{50}$ value for Switch was three times higher than the mean $\mathrm{EC}_{50}$ value for fludioxonil (data not shown). The RF for Switch was 2 times higher than fludioxonil and 3 times lower than the RF of cyprodinil. Neither an additive nor a synergistic interaction was observed between cyprodinil and fludioxonil in the mixture Switch since calculated interaction ratios were less than 0.5 for all isolates (data not shown).

Resistance phenotyping. Overall, 339 (86.5\%) and 335 (85.4\%) isolates were resistant to pyraclostrobin $\left(\mathrm{Pyra}^{\mathrm{R}}\right)$ and boscalid $\left(\right.$ Bosc $^{\mathrm{R}}$ ), respectively (Table 3). Two resistant phenotypes: high $\left(\mathrm{Pyra}^{\mathrm{HR}}, \mathrm{EC}_{50}\right.$ from 5 to $\left.500 \mu \mathrm{g} / \mathrm{ml}\right)$ and very high (Pyra ${ }^{\mathrm{VHR}}, \mathrm{EC}_{50}>$ $500 \mu \mathrm{g} / \mathrm{ml}$ ) level were distinguished for pyraclostrobin with respective frequencies of 59.5 and $40.5 \%$ (Table 3). For boscalid, a third phenotype, moderately resistant (Bosc ${ }^{\mathrm{MR}}, \mathrm{EC}_{50}$ from 5 to 50 $\mu \mathrm{g} / \mathrm{ml}$ ), was distinguished in addition to $\operatorname{Bosc}^{\mathrm{HR}}\left(\mathrm{EC}_{50}\right.$ from 50 to $500 \mu \mathrm{g} / \mathrm{ml})$ and $\operatorname{Bosc}^{\mathrm{VHR}}\left(\mathrm{EC}_{50}>500 \mu \mathrm{g} / \mathrm{ml}\right)$ phenotypes accounting for 19,39 , and $42 \%$ of the resistant isolates, respectively.

For the two APs pyrimethanil and cyprodinil, the overall resistance frequencies were 59.5 and $52.7 \%$, respectively. Overall, a majority of isolates showed a low $\left(\mathrm{EC}_{50}\right.$ from 1 to $\left.5 \mu \mathrm{g} / \mathrm{ml}\right)$ or moderate $\left(\mathrm{EC}_{50}\right.$ from 5 to $\left.10 \mu \mathrm{g} / \mathrm{ml}\right)$ resistance, whereas 24.7 and $21.2 \%$ of isolates were characterized as highly resistant $\left(\mathrm{AP}^{\mathrm{HR}}\right.$, $\mathrm{EC}_{50}>10 \mu \mathrm{g} / \mathrm{ml}$ ) to the two fungicides, respectively (Table 3). On the other hand, a majority of isolates $(78 \%)$ had an $\mathrm{EC}_{50}$ value $\leq 0.04 \mu \mathrm{g} / \mathrm{ml}$ for fludioxonil and $17.8 \%$ had an $\mathrm{EC}_{50} \geq 0.1 \mu \mathrm{g} / \mathrm{ml}$ (Table 3), whereas the frequency of isolates showing reduced sensitivity to Switch $\left(\mathrm{EC}_{50} \geq 0.1 \mu \mathrm{g} / \mathrm{ml}\right)$ was $19.8 \%$ (Table 3 ). The frequency of isolates resistant to fenhexamid was $44.4 \%$ with a majority of $65.2 \%$ of Fenh ${ }^{\mathrm{R}}$ isolates being highly resistant $\left(\mathrm{Fenh}^{\mathrm{HR}}\right.$, $\left.\mathrm{EC}_{50}>10 \mu \mathrm{g} / \mathrm{ml}\right)$.

Cross-resistance. The highest correlations were observed between Pristine and boscalid $(r=0.9506)$, Pristine and pyraclostrobin $(r=0.8898, P<0.001)$ (data not shown), as well as between boscalid and pyraclostrobin $(r=0.7954, P<0.001)$ (Table 4). An intermediate positive correlation $(r=0.537, P<0.001)$ was observed between the two APs cyprodinil and pyrimethanil. The correlations observed between pyrimethanil and both boscalid and pyraclostrobin were stronger in comparison to the correlation with cyprodinil. Significant negative cross-resistance was observed between pyraclostrobin and fludioxonil, whereas correlations observed between the other fungicides were not significant. A low positive significant correlation was observed between Switch and fludioxonil $(r=0.234)$ in contrast to Switch and cyprodinil $(r=$ 0.175 , data not shown).

Multifungicide resistance (MFR) patterns. The overall frequencies of isolates resistant to one fungicide (FR1) decreased from $21.6 \%$ in 2010 to $3.4 \%$ in 2012 (Fig. 1A). Meanwhile, the frequency of isolates showing resistance to four fungicides (MFR4) increased from 0 to $23.7 \%$. The isolates showing resistance to three (MFR3) and two (MFR2) fungicides, respectively, were predominant every year (Fig. 1A). Among the FR1 isolates, 43.5, 26.1, 26.1, and 4.3\% of isolates were resistant to Bosc, QoI, Hyd, and AP fungicides, respectively (Fig. 1B). In the MFR2 phenotype, $87.4 \%$ of the isolates were Bosc-QoI ${ }^{\mathrm{R}}$, whereas a low frequency included Bosc-Hyd ${ }^{\mathrm{R}}(5.4 \%)$, QoI-AP ${ }^{\mathrm{R}}(2.7 \%)$, QoI-Hyd ${ }^{\mathrm{R}}$ $(2.7 \%)$, or Bosc-AP $\mathrm{AP}^{\mathrm{R}}(1.8 \%)$ isolates. The MFR3 phenotype included the Bosc-QoI-APR ${ }^{\mathrm{R}}$ the Bosc-QoI-Hyd ${ }^{\mathrm{R}}$, the Bosc-Hyd$\mathrm{AP}^{\mathrm{R}}$, and the QoI-Hyd-AP ${ }^{\mathrm{R}}$ isolates with respective frequencies of $56.5,40.5,1.8$, and $1.2 \%$, whereas the MFR4 phenotype included the Bosc-QoI-Hyd-AP ${ }^{\mathrm{R}}$ isolates (Fig. 1B).

Among isolates collected in 2010, the FR1 and MFR2 isolates were more frequent in all surveyed locations with the exception of the GC field, where MFR3 isolates were more abundant than MFR2 isolates (Fig. 2). An increase in the frequency of MFR3 isolates was observed in all locations in 2011, and this phenotype was predominant except for the PC, BI, and FY locations. MFR4 isolates were absent from all locations in 2010 but were present in three and five locations in 2011 and 2012, respectively (Fig. 2). The highest frequencies of MFR4 isolates were 32 and $50 \%$ and were recorded in the SS and BI locations, respectively, in 2012.

Fruit assay. All sensitive isolates were controlled by the recommended field rate of each fungicide (Table 5). Isolates characterized as highly resistant (HR) and very highly resistant (VHR) to boscalid and pyraclostrobin caused 50 to $100 \%$ disease incidence on fruit sprayed preventively with either fungicide. Isolates with $\mathrm{EC}_{50}$ values lower than $5 \mu \mathrm{g} / \mathrm{ml}$ for pyrimethanil, cyprodinil, and fenhexamid inoculated on strawberry fruit were controlled with the field rates of the respective fungicides applied preventively (Table 5 ). Gray mold incidence and severity were $\geq 50 \%$ in all cases, and more specifically, for pyrimethanil $(>66 \%)$ and cyprodinil (>83.3\%) when fruit were inoculated with isolates exhibiting $\mathrm{EC}_{50}$ values higher than those mentioned above. Only $\mathrm{Fenh}^{\mathrm{HR}}$ isolates were not controlled by fenhexamid. All isolates inoculated on fruit were controlled by fludioxonil (Medallion) and cyprodinil + fludioxonil (Switch) regardless of their $\mathrm{EC}_{50}$ value to these two fungicides (data not shown).

\section{Discussion}

Populations of $B$. cinerea very highly resistant $\left(\mathrm{EC}_{50}>500\right.$ $\mu \mathrm{g} / \mathrm{ml}$ ) to boscalid and pyraclostrobin, two components of a common fungicide used continuously in Florida strawberry fields since

Table 4. Cross-resistance patterns between fungicides in Botrytis cinerea isolates from strawberry fields in Florida

\begin{tabular}{|c|c|c|c|c|c|c|c|c|c|c|}
\hline \multirow[b]{3}{*}{ Fungicide } & \multicolumn{10}{|c|}{ Fungicide } \\
\hline & \multicolumn{2}{|c|}{ Boscalid } & \multicolumn{2}{|c|}{ Pyraclostrobin } & \multicolumn{2}{|c|}{ Cyprodinil } & \multicolumn{2}{|c|}{ Fludioxonil } & \multicolumn{2}{|c|}{ Switch } \\
\hline & $r^{\mathbf{z}}$ & $P$ & $r$ & $P$ & $r$ & $P$ & $r$ & $P$ & $r$ & $P$ \\
\hline Boscalid & & & 0.7954 & $<0.001$ & 0.1061 & 0.334 & -0.1951 & 0.073 & 0.0097 & 0.929 \\
\hline Pyraclostrobin & 0.7954 & $<0.001$ & & & 0.0836 & 0.448 & -0.3161 & 0.003 & -0.0475 & 0.665 \\
\hline Pyrimethanil & 0.3053 & 0.004 & 0.3546 & $<0.001$ & 0.537 & $<0.001$ & -0.09 & 0.407 & 0.117 & 0.285 \\
\hline Cyprodinil & 0.1961 & 0.034 & 0.1836 & 0.048 & & 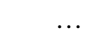 & 0.175 & 0.108 & 0.153 & 0.160 \\
\hline Fludioxonil & -0.1951 & 0.073 & -0.3161 & 0.003 & 0.175 & 0.108 & $\ldots$ & & 0.234 & 0.030 \\
\hline Fenhexamid & -0.2388 & 0.027 & -0.1461 & 0.182 & 0.010 & 0.922 & 0.063 & 0.563 & 0.027 & 0.801 \\
\hline
\end{tabular}

${ }^{\mathrm{z}}$ Pearson correlation coefficients were calculated by $\log _{10} \mathrm{EC}_{50}$ values of 150 isolates collected in 2010 and 2012. 
2004, were reported in this study. Consequently, even higher rates of these fungicides will not control the large portion of Bosc $\mathrm{BHR}^{\mathrm{VH}}$ $(42 \%)$ or Pyra $^{\mathrm{VHR}}(40.5 \%)$ isolates. The high resistance frequencies (>80\%) observed for the QoIs in Florida agree with previous reports from strawberry fields in Japan (18), Greece (37), Germany (40), and the Carolinas (12), but not with lower resistance frequencies from apples, grapes, and multiple other crops $(19,21,28,41)$. Resistance frequency observed for boscalid in Florida is equivalent to that reported from strawberry fields in the Carolinas (12) and Greece (39), but much higher compared to those reported from apple orchards in Washington State, vegetable fields in Greece, and berry farms in Northern Germany, where boscalid has been sprayed once or twice a season only and resistance frequencies as low as $20 \%$ have been reported $(35,40-42)$. A different genetic background of $B$. cinerea populations from the southeastern U.S. strawberry fields coupled with more intensive spray programs could have influenced the selection for higher resistance frequencies in this region. The positive cross-resistance observed herein between boscalid and pyraclostrobin confirms similar previous reports in vitro $(4,19)$. This may also suggest a role for pyraclostrobin and the other QoIs, which have been sprayed intensively in Florida since 1998 to control other major diseases such as powdery mildew and anthracnose fruit rot, in selecting for Bosc ${ }^{\mathrm{R}}$-populations in the field. It is likely that the small fraction of isolates resistant to boscalid but sensitive to pyraclostrobin carry an intron, reported to impede resistance development to the QoI, after codon 143 of the $c y t b$ gene $(19,28)$. The lack of variability in phenotypes of $\mathrm{QoI}^{\mathrm{R}}$ isolates in contrast to $\mathrm{Bosc}^{\mathrm{R}}$ isolates from Florida suggests that a single mutation in the cytochrome $b$ gene is likely responsible for QoI resistance development, whereas multiple point mutations in the succinate dehydrogenase $S D H$ gene may be involved in resistance to boscalid as reported previously $(28,37,39,41,42)$.

Pyrimethanil (Scala) and cyprodinil, a component of Switch, have been regularly sprayed in Florida strawberry fields between 2004 and 2012, during which resistant populations were selected and became widespread. Resistance frequencies for the two APs were similar to those reported previously from grapes in Switzerland (5) and from vegetable crops in Greece (35). Overall, the $\mathrm{AP}^{\mathrm{S}}$ and the $\mathrm{AP}^{\mathrm{LR}}$ phenotypes were more frequent than the $\mathrm{AP}^{\mathrm{MR}}$ and the $\mathrm{AP}^{\mathrm{HR}}$ phenotypes in Florida. The fact that only isolates from the latter two phenotypes were not controlled on detached fruit sprayed with the recommended field rates implies that these two fungicides could still control a large portion of isolates in the field if appropriate spray programs are implemented to reduce the risk of selecting more resistant isolates. Interestingly, and in accordance with previous reports $(14,24,35)$, about $7 \%$ of isolates resistant to pyrimethanil were sensitive to cyprodinil. This may explain, in part, that the correlation $(r=0.537)$ between these two fungicides is not as high as it is usually expected to be between active ingredients from the same chemical group. The lower intrinsic activity of pyrimethanil may result from differences in the up-take and detoxification of the two APs by the fungus. Pyrimethanil was registered before cyprodinil (in Switch) for gray mold control in Florida. However, a single application of Switch, containing cyprodinil, per year was found to be enough to create a shift toward reduced sensitivity to cyprodinil, and the risk was doubled with two applications per year (5).

There was no clear evidence for a shift toward resistance to fludioxonil in isolates of $B$. cinerea from strawberry. All RS isolates $\left(\mathrm{EC}_{50} \geq 0.1 \mu \mathrm{g} / \mathrm{ml}\right)$ to fludioxonil or Switch were controlled by both fungicides on detached fruit. It is obvious that fludioxonil

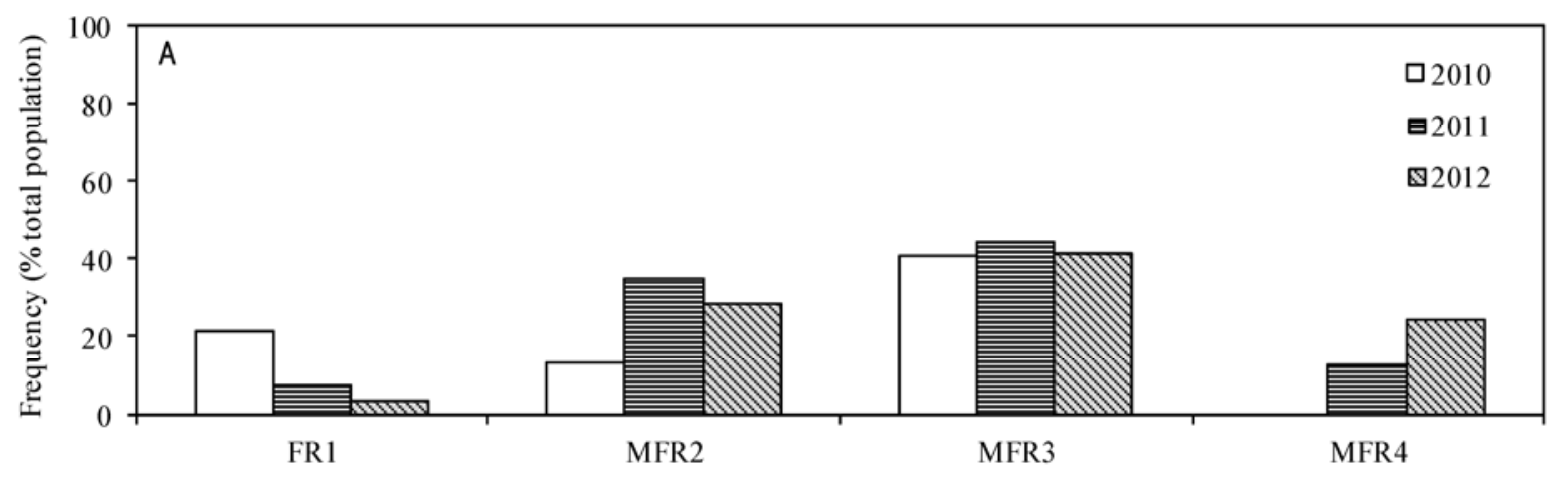

Multifungicide phenotype

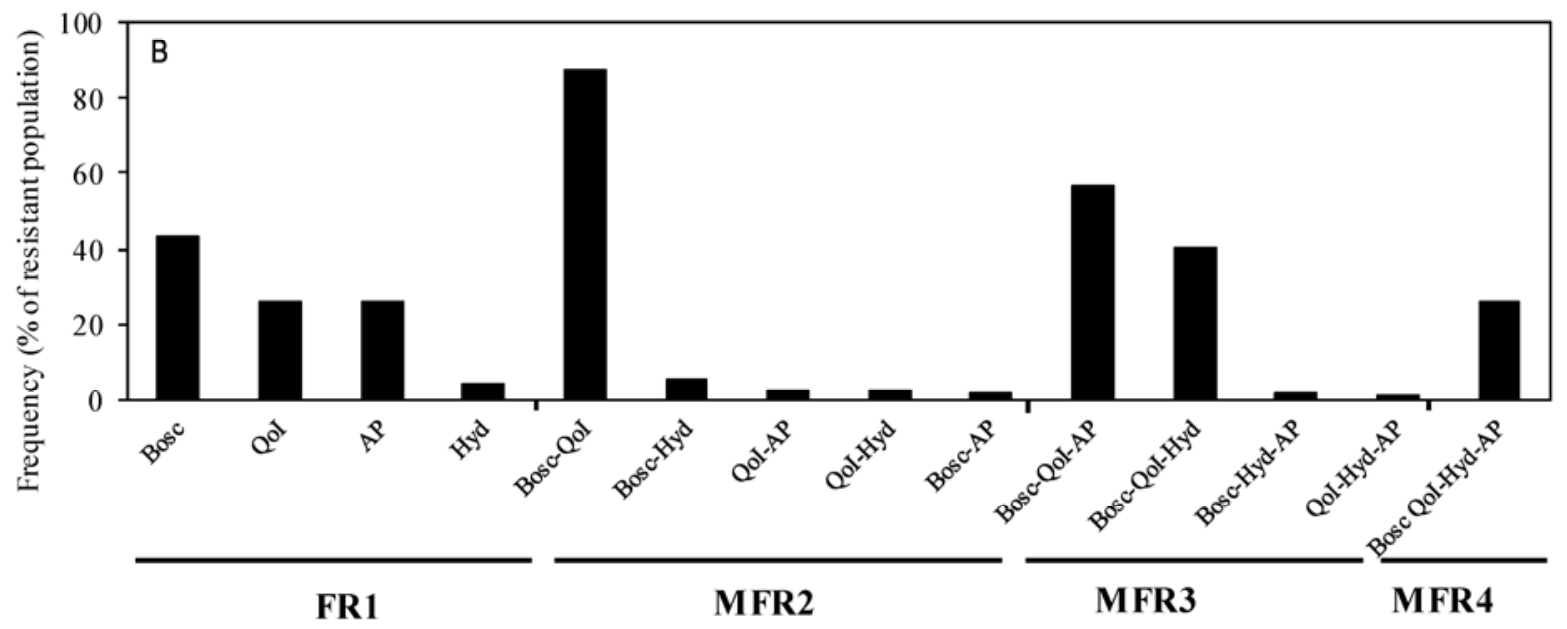

Fig. 1. A, Overall frequency of multifungicide resistance (MFR) phenotypes and B, frequency distribution of MFR phenotypes observed in Botrytis cinerea populations across 10 strawberry fields in Florida $(n=392)$ between 2010 and 2012. FR1 indicates resistance to a single fungicide, whereas MFR2, MFR3, and MFR4 indicate isolates that are resistant to two, three, and four fungicides from different chemical groups, respectively. Qol, Sdhl, Hyd, and AP indicate quinone-outside inhibitor, succinate dehydrogenase inhibitor, hydroxyanilide, and anilinopyrimidine, respectively. 
is the most active fungicide available currently for gray mold management. However, under weather conditions conducive to gray mold such as those that occurred in February 2012 in Florida, the activity of fludioxonil may not be sufficient to control severe epidemics, especially in fields where the fungicide is not sprayed at bloom, a key growth stage for gray mold control on strawberry. Field resistance to fludioxonil has been reported to date only in Penicillium digitatum (20), likely due to the complexity of the biochemical and molecular mechanisms involved in its activity (44) and the fitness penalties associated with reduced sensitivity to fludioxonil. Nonetheless, limited applications of fludioxonil, the sole active ingredient to which no resistance is apparent, and continuous monitoring of its resistance are highly recommended to avoid an unexpected shift toward field resistance. Neither additive nor synergistic effects were observed between the two active ingredients in Switch and Pristine as well. This raises a critical question about the impact of co-formulated fungicides on selecting for multiple resistant populations, especially for "high risk" pathogens such as $B$. cinerea, since no beneficial effect of the mixtures has been evidenced in this or in previous studies (21). The same conclusions also may be valid for the new SdhI-fluxapyroxad that is expected to be co-formulated with pyraclostrobin in the new fungicide Merivon (BASF Crop Protection). Knowing the widespread distribution of QoI ${ }^{\mathrm{R}}$ populations in Florida and elsewhere, it is crucial to determine if resistance to the QoIs would hasten resistance development to the new SdhIs.

Applications of fenhexamid over the peak bloom period in the 1999 and 2000 seasons in experimental plots in Florida significantly improved gray mold control and increased marketable yield (26). After a decade of use, populations resistant to fenhexamid have emerged, and a quick shift toward resistance has occurred in the last 2 years as evidenced herein. Following the decrease in the efficacy of boscalid and QoIs, fenhexamid has been used more frequently in recent years in Florida, which increased the resistance frequency from $2.9 \%$ in 2010 to $38.6 \%$ in 2012 . The two phenotypes Fenh ${ }^{\mathrm{MR}}\left(\mathrm{EC}_{50}\right.$ from 1 to $\left.<10 \mu \mathrm{g} / \mathrm{ml}\right)$ and Fenh ${ }^{\mathrm{HR}}\left(\mathrm{EC}_{50} \geq 10\right.$ $\mu \mathrm{g} / \mathrm{ml})$ reported herein agree with the phenotypes reported in previous studies $(11,13,40)$. Based on the results from this study, fenhexamid will not control Fenh ${ }^{\mathrm{HR}}$ isolates in the field unless resistant isolates fail to survive under field conditions as was documented recently under controlled conditions (6). In contrast to the other fungicides surveyed in this study, resistance to fenhexamid


Fig. 2. Temporal change in frequency of multifungicide resistance (MFR) phenotypes observed in Botrytis cinerea isolates $(n=296)$ collected between 2010 and 2012 from six strawberry fields (GC, PC, SS, AN, BI, FY) in Florida. FR1 indicates resistance to a single fungicide, whereas MFR2, MFR3, and MFR4 indicate isolates that are resistant to two, three, and four fungicides, respectively. 
was not found in all locations, presumably because of different spray programs used among locations. Therefore, additional precautions should be taken such as determining the site-specific resistance profiles for more appropriate spray recommendations. The best rotation scenarios would include fenhexamid with fludioxonil and the new SdhIs fluopyram, penthiopyrad, and fluxapyroxad that are expected to be registered soon for gray mold management.

Four MFR phenotypes were detected in $B$. cinerea populations in Florida. The FR1 isolates diminished in frequency and were progressively replaced by the MFR2 and MFR3 isolates. It is clear from these results that the SdhI-boscalid, the QoIs, and the APs would not control a large portion of isolates present in Florida fields. The predominance of Bosc-QoI ${ }^{\mathrm{R}}$ isolates $(87.4 \%)$ among the MFR2 isolates as evidenced by the strong cross-resistance observed between these two fungicides is certainly a result of a simultaneous selection of QoI-Bosc resistant populations following 8 years of Pristine use in Florida, especially since QoI ${ }^{\mathrm{R}}$ isolates were found to be more fitted to develop resistance to the SdhIs $(4,19)$. Moreover, although the SdhIs and QoIs target the mitochondrial complexes II and III, respectively, both complexes are involved in electron transfer and are structurally interconnected. Knowing the history of resistance of $B$. cinerea to benzimidazoles (BZI) in Florida (N. Peres, personal observation) and the low frequency of FR1 isolates found in this study, it is likely that Bosc-QoI ${ }^{\mathrm{R}}$ have been selected from a population already resistant to certain fungicides such as the BZIs. A predominant population (MFR3) seems to have evolved from the MFR2 population and split into two subpopulations. The frequent use of the APs since 2003 in Florida has selected for the predominant MFR3 population Bosc-QoI-AP ${ }^{\mathrm{R}}(57 \%)$ in comparison to the Bosc-QoI$\mathrm{Hyd}^{\mathrm{R}}$ isolates $(41 \%)$. This may reflect, in part, the stronger resistance correlation observed between the two APs and the QoIs and boscalid compared to the Hyd. Recently, a MFR4 population (23\%), which would be controlled by fludioxonil only, has been selected across almost all locations surveyed as a consequence of the advent of resistance to fenhexamid (A. Amiri, S. M. Heath, and N. A. Peres, unpublished). It is interesting to note that the APs seem to exercise a much stronger selection pressure compared to the Hyd, since the latter was in use several years before the APs. While the molecular mechanism involved in resistance to the APs is still unknown, the resistance to the Hyd has been linked to a point mutation in the erg27 gene encoding the 3-ketoreductase enzyme (13; A. Amiri, S. M. Heath, and N. A. Peres, unpublished). The resistance to fenhexamid does not seem to fit the traditional qualitative resistance development usually associated with single point mutations as was the case for the BZIs and the SdhIs. Therefore, the presence of another mechanism of resistance that may hamper selection for $\mathrm{Hyd}^{\mathrm{R}}$ populations is unknown but possible. In a comparable study in French and German vineyards, three resistant phenotypes, MDR1 (multidrug resistance), MDR2, and MDR3, involving positive cross-resistance between unrelated fungicides, have been characterized in $B$. cinerea populations $(23,31)$. The MDR1 showed a reduced sensitivity to PP, AP, and the dicarboxamide (Dic) iprodione, the MDR2 showed reduced sensitivity to AP, Hyd, and Dic, whereas the MDR3 isolates, resistant to most fungicides, are thought to be a genetic combination of the MDR1 and MDR2 (23). An overexpression of a major facilitator superfamily transporter gene $m f s \mathrm{M} 2$ and mutations occurring within its promoter have been suggested to cause the MDR2 isolates to become resistant to the three chemical classes mentioned previously $(23,31)$. In our study, a majority of isolates (20) that showed reduced sensitivity to fludioxonil were also MFR4 but were all controlled by fludioxonil on detached fruits. Because of the control failure that growers experienced in Florida in 2012 and the widespread resistance observed in the present study to most fungicides, fludioxonil will be a key constituent of gray mold management programs in the years to come. Therefore, determining the impact of rotating fludioxonil with other fungicides on selecting for resistance, especially among the predominant MFR3 and MFR4 isolates, and the ability of MFR isolates to survive and evolve to more resistant populations under field conditions would help in developing more appropriate spray programs.

The overall frequency of MFR populations in Florida strawberry fields without considering the Bosc-QoI ${ }^{\mathrm{R}}$ phenotypes was $56.5 \%$ of

Table 5. Efficacy of fungicides in controlling gray mold on strawberry fruit inoculated with Botrytis cinerea isolates with different levels of sensitivity

\begin{tabular}{|c|c|c|c|c|c|}
\hline \multirow[b]{2}{*}{ Fungicide $^{y}$} & \multirow[b]{2}{*}{ Isolate } & \multirow[b]{2}{*}{$\mathrm{EC}_{50}(\mu \mathrm{g} / \mathrm{ml})$} & \multirow[b]{2}{*}{ Phenotype $^{\mathrm{z}}$} & \multicolumn{2}{|c|}{ Gray mold $^{x}(\%)$} \\
\hline & & & & Incidence & Severity \\
\hline Pyraclostrobin & $\begin{array}{l}05-31 \\
05-29 \\
10-38 \\
11-37 \\
10-43\end{array}$ & $\begin{array}{r}0.17 \\
0.59 \\
6.25 \\
123.31 \\
606.12\end{array}$ & $\begin{array}{c}\text { S } \\
S \\
\text { HR } \\
\text { HR } \\
\text { VHR }\end{array}$ & $\begin{array}{l}0.0 \mathrm{a} \\
0.0 \mathrm{a} \\
100 \mathrm{~b} \\
100 \mathrm{~b} \\
100 \mathrm{~b}\end{array}$ & $\begin{array}{c}0.0 \\
0.0 \\
100 \\
70.3 \\
82.2\end{array}$ \\
\hline Boscalid & $\begin{array}{l}05-29 \\
11-26 \\
07-66 \\
11-50 \\
10-35\end{array}$ & $\begin{array}{c}0.89 \\
1.70 \\
13.3 \\
326.41 \\
562.01\end{array}$ & $\begin{array}{c}\text { S } \\
\text { MR } \\
\text { MR } \\
\text { HR } \\
\text { VHR }\end{array}$ & $\begin{array}{c}0.0 \mathrm{a} \\
0.0 \mathrm{a} \\
0.0 \mathrm{a} \\
52.8 \mathrm{~b} \\
100 \mathrm{c}\end{array}$ & $\begin{array}{r}0.0 \\
0.0 \\
0.0 \\
50.7 \\
87.2\end{array}$ \\
\hline Pyrimethanil & $\begin{array}{l}07-64 \\
08-99 \\
10-34 \\
10-33\end{array}$ & $\begin{array}{c}<1.79 \\
2.79 \\
6.10 \\
26.9\end{array}$ & $\begin{array}{c}\mathrm{S} \\
\mathrm{S} \\
\mathrm{MR} \\
\mathrm{HR}\end{array}$ & $\begin{array}{c}0.0 \mathrm{a} \\
0.0 \mathrm{a} \\
66.7 \mathrm{~b} \\
100 \mathrm{c}\end{array}$ & $\begin{array}{r}0.0 \\
0.0 \\
68.2 \\
98.2\end{array}$ \\
\hline Cyprodinil & $\begin{array}{c}08-96 \\
05-251 \\
07-65 \\
10-34\end{array}$ & $\begin{array}{r}2.70 \\
3.20 \\
6.30 \\
13.57\end{array}$ & $\begin{array}{c}\text { S } \\
\text { S } \\
\text { MR } \\
\text { HR }\end{array}$ & $\begin{array}{r}0.0 \mathrm{a} \\
0.0 \mathrm{a} \\
83.3 \mathrm{~b} \\
100.0 \mathrm{~b}\end{array}$ & $\begin{array}{r}0.0 \\
0.0 \\
83.2 \\
91.3\end{array}$ \\
\hline Fenhexamid & $\begin{array}{c}05-25 \\
08-98 \\
10-34 \\
11-48 \\
\end{array}$ & $\begin{array}{r}0.12 \\
1.56 \\
10.75 \\
12.54 \\
\end{array}$ & $\begin{array}{c}\text { S } \\
\text { MR } \\
\text { HR } \\
\text { HR } \\
\end{array}$ & $\begin{array}{r}0.0 \mathrm{a} \\
0.0 \mathrm{a} \\
50.0 \mathrm{~b} \\
75.0 \mathrm{~b}\end{array}$ & $\begin{array}{r}0.0 \\
0.0 \\
68.9 \\
92.4 \\
\end{array}$ \\
\hline
\end{tabular}

\footnotetext{
${ }^{x}$ Gray mold incidence was estimated in comparison to the nontreated control. Data are the means of six values across two experimental runs. Gray mold incidence values followed by the same letters for each fungicide separately are not significantly different based on ANOVA and LSD test at $P \leq 0.05$.

${ }^{y}$ Fruit never sprayed with any fungicide were surface-sterilized and wounded near the calix area. Fruit were sprayed preventively with pyraclostrobin (Cabrio), boscalid (Endura), cyprodinil (Vanguard), and fenhexamid (Elevate) at 1.09, 0.86, 0.7, and $1.8 \mathrm{~g} /$ liter, respectively. Pyrimethanil was applied as Scala at $1.4 \mathrm{ml} /$ liter. Fruit were incubated overnight at room temperature and inoculated with a $40-\mu \mathrm{l}$ droplet of conidial suspension at $10^{6} \mathrm{conidia} / \mathrm{ml}$ from each isolate. Incidence and severity of gray mold was evaluated after 4 to 5 days of incubation at $24^{\circ} \mathrm{C}$. Data for fludioxonil and Switch are not shown.

${ }^{z} \mathrm{~S}, \mathrm{MR}$, and HR indicate sensitive, moderately resistant, and highly resistant, respectively.
} 
the total population, equivalent to $55 \%$ of multiple resistant populations found in French vineyards (23) but higher than 35 to $38 \%$ reported in German vineyards (23) and kiwi orchards in Greece (4). However, adding the Bosc-QoI ${ }^{\mathrm{R}}$ phenotypes increases the frequency of MFR to $70 \%$ of the total population in Florida. To the best of our knowledge, applications of the same fungicide have been limited to one per year in most European vineyards several years ago, whereas some fungicides are still sprayed four to six times a year in Florida. The overall fungicide resistance situation in Florida may be worsened by several factors. First, strawberry production in Florida is intensive and with up to $90 \%$ of the fields situated within a 50-km perimeter around Plant City and Dover. This may increase the risk of cross-contamination and gene flow between fields where different spray regimes are observed. Moreover, it is possible that new populations of $B$. cinerea are being introduced every year to Florida via the strawberry plantlets shipped from different nurseries in North America. It is, however, unknown if part of the potential new inoculum is already resistant to certain fungicides commonly used in nurseries. Ultimately, it is possible that MFR isolates are being spread when strawberries carrying latent infections are shipped from Florida to other regions.

Our data substantiate widespread resistance to multiple fungicides in $B$. cinerea on strawberries and explain in part the recent gray mold epidemic that has spread across Florida fields. This new situation requires drastic behavioral changes in gray mold management including changes in fungicide spray regulations and recommendations. Continuous research and monitoring efforts will be necessary in the future to evaluate the risks associated with such widespread resistance as well as developing new strategies to avoid the selection of more highly resistant populations.

\section{Acknowledgments}

This research was supported by a USDA-NIFA fund under project No. 201051181-21113. We thank Juliana Baggio and Robert Martin for technical assistance.

\section{Literature Cited}

1. Abbot, W. S. 1925. A method of computing the effectiveness of an insecticide. J. Econ. Entomol. 18:265-267.

2. Albertini, C., and Leroux, P. 2004. A Botrytis cinerea putative 3-keto reductase gene (ERG27) that is homologous to the mammalian 17 beta-hydroxysteroid dehydrogenase type 7 gene (17 beta-HSD7). Eur. J. Plant Pathol. 110:723-733.

3. Amiri, A., Brannen, P. M., and Schnabel, G. 2010. Reduced sensitivity in Monilinia fructicola field isolates from South Carolina and Georgia to respiration inhibitor fungicides. Plant Dis. 94:737-743.

4. Bardas, G. A., Veloukas, T., Koutiba, O., and Karaoglanidis, G. S. 2010. Multiple resistance of Botrytis cinerea from kiwifruit to SdhIs, QoIs and fungicides of other chemical groups. Pest Manag. Sci. 66:967-973.

5. Baroffio, C. A., Siegfried, W., and Hilber, U. W. 2003. Long-term monitoring for resistance of Botryotinia fuckeliana to anilinopyrimidine, phenylpyrrole, and hydroxyanilide fungicides in Switzerland. Plant Dis. 87:662666.

6. Billard, A., Fillinger, S., Leroux, P., Lachaise, H., Beffa, R., and Debieu, D. 2011. Strong evidence to the fungicide fenhexamid entails a fitness cost in Botrytis cinerea, as shown by comparisons of isogenic strains. Pest Manag. Sci. 68:684-691.

7. Braun, P. G., and Sutton, J. C. 1987. Inoculum sources of Botrytis cinerea in fruit rot of strawberries in Ontario. Can. J. Plant Pathol. 9:1-5.

8. Bristow, P. R., McNicol, R. J., and Williamson, B. 1986. Infection of strawberry flowers by Botrytis cinerea and its relevance to grey mould development. Ann. Appl. Biol. 109:545-554.

9. Debieu, D., Bach, J., Hugon, M., Malosse, C., and Leroux, P. 2001. The hydroxyanilide fenhexamid, a new sterol biosynthesis inhibitor fungicide efficient against the plant pathogenic fungus Botryotinia fuckeliana (Botrytis cinerea). Pest Manag. Sci. 57:1060-1067.

10. Esterio, M., Auger, J., Ramos, C., and García, H. 2007. First report of fenhexamid resistant isolates of Botrytis cinerea on grapevine in Chile. Plant Dis. 91:768.

11. Esterio, M., Ramos, C., Walker, A. S., Fillinger, S., Leroux, P., and Auger, J. 2011. Phenotypic and genetic characterization of Chilean isolates of Botrytis cinerea with different levels of sensitivity to fenhexamid. Phytopathol. Mediterr. 50:414-420.

12. Fernández-Ortuño, D., Chen, F., and Schnabel, G. 2012. Resistance to pyraclostrobin and boscalid in Botrytis cinerea isolates from strawberry fields in the Carolinas. Plant Dis. 96:1198-1203.

13. Fillinger, S., Leroux, P., Auclair, C., Barreau, C., Al Hajj, C., and Debieu,
D. 2008. Genetic analysis of fenhexamid-resistant field isolates of the phytopathogenic fungus Botrytis cinerea. Antimicrob. Agents Chem. 52:3933-3940.

14. Forster, B., and Staub, T. 1996. Basis for use strategies of anilinopyrimidine and phenylpyrrole fungicides against Botrytis cinerea. Crop Prot. 15:529537.

15. Förster, H., Kanetis, L., and Adaskaveg, J. E. 2004. Spiral gradient dilution, a rapid method for determining growth responses and $50 \%$ effective concentration values in fungus-fungicide interactions. Phytopathology 94:163-170.

16. Heye, U. J., Speich, J., Siegle, H., Steinemann, A., Forster, B., KnaufBeiter, G., Herzog, J., and Hubele, A. 1994. CGA 219417: A novel broadspectrum fungicide. Crop Prot. 13:541-549.

17. Hilber, U. W., Schüepp, H., and Schwinn, F. J. 1994. Resistance risk evaluation of fludioxonil, a new phenylpyrrole fungicide. Pages 397-402 in: Fungicide Resistance BCPC Monogr. No. 60. S. Heaney, D. Slawson, D. W. Hollomon, M. Smith, P. E. Russell, and D. W. Parry, eds. British Crop Protection Council, Surrey, England.

18. Ishii, H., Fountaine, J., Chung, W. H., Kansako, M., Nishimura, K., Takahashi, K., and Oshima, M. 2009. Characterisation of QoI-resistant field isolates of Botrytis cinerea from citrus and strawberry. Pest Manag. Sci. 65:916-922.

19. Jiang, J. H., Ding, L. S., Michailides, T. J., Li, H. Y., and Ma, Z. H. 2009. Molecular characterization of field azoxystrobin-resistant isolates of Botrytis cinerea. Pest. Biochem. Physiol. 93:72-76.

20. Kanetis, L., Forster, H., Jones, C. A., Borkovich, K. A., and Adaskaveg, J. E. 2008. Characterization of genetic and biochemical mechanisms of fludioxonil and pyrimethanil resistance in field isolates of Penicillium digitatum. Phytopathology 98:205-214.

21. Kim, Y. K., and Xiao, C. L. 2010. Resistance to pyraclostrobin and boscalid in populations of Botrytis cinerea from stored apples in Washington State. Plant Dis. 94:604-612.

22. Köller, W. 1992. Antifungal agents with target sites in sterol function and biosynthesis. Pages 119-206 in: Target Sites of Fungicide Action. W. Köller, ed. CRC Press, Boca Raton, FL.

23. Kretschmer, M., Leroch, M., Mosbach, A., Walker, A. S., Fillinger, S., Mernke, D., Schoonbeek, H. J., Pradier, J. M., Leroux, P., De Waard, M. A., and Hahn, M. 2009. Fungicide-driven evolution and molecular basis of multidrug resistance in field populations of the grey mould fungus Botrytis cinerea. Plos Pathog. 5:1-13.

24. Latorre, B. A., Spadaro, I., and Rioja, M. E. 2002. Occurrence of resistant strains of Botrytis cinerea to anilinopyrimidine fungicides in table grapes in Chile. Crop Prot. 21:957-961.

25. Legard, D. E., and Chandler, C. K. 2000. Evaluation of fungicides to control Botrytis fruit rot of strawberry, 1998. Fungic. Nematicide Tests 55:124-125.

26. Legard, D. E., MacKenzie, S. J., Mertely, J. C., Chandler, C. K., and Peres, N. A. 2005. Development of a reduced use fungicide program for control of Botrytis fruit rot on annual winter strawberry. Plant Dis. 89:1353-1358.

27. Leroux, P., Chapeland, F., Desbrosses, D., and Gredt, M. 1999. Patterns of cross-resistance to fungicides in Botryotinia fuckeliana (Botrytis cinerea) isolates from French vineyards. Crop Prot. 18:687-697.

28. Leroux, P., Gredt, M., Leroch, M., and Walker, A. S. 2010. Exploring mechanisms of resistance to respiratory inhibitors in field strains of Botrytis cinerea, the causal agent of gray mold. Appl. Environ. Microbiol. 76:66156630 .

29. Malandrakis, A., Markoglou, A., and Ziogas, B. 2011. Molecular characterization of benzimidazole-resistant $B$. cinerea field isolates with reduced or enhanced sensitivity to zoxamide and diethofencarb. Pest. Biochem. Physiol. 99:118-124.

30. Masner, P., Muster, P., and Schmid, J. 1994. Methionine biosynthesis inhibition by pyrimidinamine fungicides in Botrytis cinerea. Pestic. Sci. 42:163 166.

31. Mernke, D., Dahm, S., Walker, A.-S., Lalève, A., Fillinger, S., Leroch, M., and Hahn, M. 2011. Two promoter rearrangements in a drug efflux transporter gene are responsible for the appearance and spread of multidrug resistance phenotype MDR2 in Botrytis cinerea isolates in French and German vineyards. Phytopathology 101:1176-1183.

32. Mertely, J. C., MacKenzie, S. J., and Legard, D. E. 2002. Timing of fungicide applications for Botrytis cinerea based on development stage of strawberry flowers and fruit. Plant Dis. 86:1019-1024.

33. Mertely, J. C., and Peres, N. A. 2009. Botrytis fruit rot or gray mold of strawberry. Page 230 in: Plant Pathology Department series, Florida Cooperative Extension Service, Institute of Food and Agricultural (IFAS), Gainesville, FL.

34. Mertely, J. C., Peres, N. A., and Chandler, C. K. 2009. Anthracnose fruit rot of strawberry. Page 207 in: Plant Pathology Department, Florida Cooperative Extension Service, Institute of Food and Agricultural Sciences (IFAS), University of Florida. Gainesville, FL.

35. Myresiotis, C. K., Karaoglanidis, G. S., and Tzavella-Klonari, K. 2007. Resistance of Botrytis cinerea isolates from vegetable crops to anilinopyrimidine, phenylpyrrole, hydroxyanilide, benzimidazole, and dicarboximide fungicides. Plant Dis. 91:407-413.

36. Pillonel, C., and Meyer, T. 1997. Effect of phenylpyrroles on glycerol accumulation and protein kinase activity of Neurospora crassa. Pestic. 
Sci. 49:229-236.

37. Samuel, S., Papayiannis, L. C., Leroch, M., Veloukas, T., Hahn, M., and Karaoglanidis, G. S. 2011. Evaluation of the incidence of the G143A mutation and $c y t b$ intron presence in the cytochrome $b c-1$ gene conferring QoI resistance in Botrytis cinerea populations from several hosts. Pest Manag. Sci. 67:1029-1036.

38. Santos, B. M., Peres, N. A., Price, J. F., Chandler, C. K., Withaker, V. W., Stall, W. M., Olson, S. A., and Smith and Simone, E. H. 2011. Strawberry production in Florida. Pages 271-282 in: Vegetable Production Handbook for Florida. University of Florida-IFAS Extension, Gainesville, FL.

39. Veloukas, T., Leroch, M., Hahn, M., and Karaoglanidis, G. S. 2011. Detection and molecular characterization of boscalid-resistant Botrytis cinerea isolates from strawberry. Plant Dis. 95:1302-1307.

40. Weber, R. W. S. 2011. Resistance of Botrytis cinerea to multiple fungicides in Northern German small-fruit production. Plant Dis. 95:1263-1269.

41. Yin, Y. N., Kim, Y. K., and Xiao, C. L. 2011. Molecular characterization of boscalid resistance in field isolates of Botrytis cinerea from apple. Phytopathology 101:986-995.

42. Yin, Y. N., Kim, Y. K., and Xiao, C. L. 2012. Molecular characterization of pyraclostrobin resistance and structural diversity of the cytochrome $b$ gene in Botrytis cinerea from apple. Phytopathology 102:315-322.

43. Zhao, H., Kim, Y. K., Huang, L., and Xiao, C. L. 2010. Resistance to thiabendazole and baseline sensitivity to fludioxonil and pyrimethanil in Botrytis cinerea populations from apple and pear in Washington State Postharv. Biol. Technol. 56:12-18.

44. Ziogas, B. N., Markoglou, A. N., and Spyropoulou, V. 2005. Effect of phenylpyrrole-resistance mutations on ecological fitness of Botrytis cinerea and their genetical basis in Ustilago maydis. Eur. J. Plant Pathol. 113:83-100. 